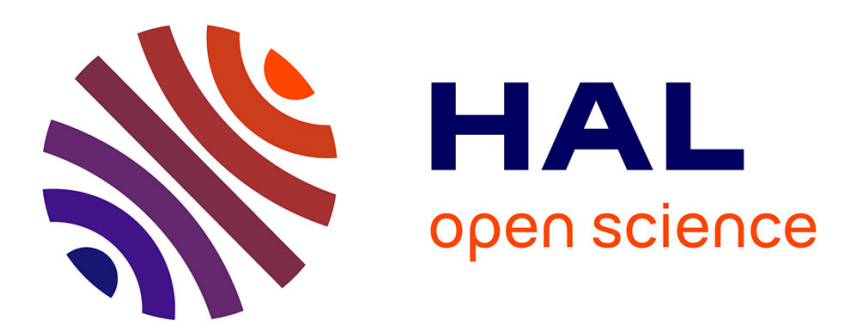

\title{
Early and Adult Social Environments Shape Sex-Specific Actuarial Senescence Patterns in a Cooperative Breeder
}

Vérane Berger, Jean-François Lemaître, Dominique Allainé, Jean-Michel Gaillard, Aurélie Cohas

\section{- To cite this version:}

Vérane Berger, Jean-François Lemaître, Dominique Allainé, Jean-Michel Gaillard, Aurélie Cohas. Early and Adult Social Environments Shape Sex-Specific Actuarial Senescence Patterns in a Cooperative Breeder. The American Naturalist, 2018. hal-01891757

\section{HAL Id: hal-01891757 https: / univ-lyon1.hal.science/hal-01891757}

Submitted on 9 Oct 2018

HAL is a multi-disciplinary open access archive for the deposit and dissemination of scientific research documents, whether they are published or not. The documents may come from teaching and research institutions in France or abroad, or from public or private research centers.
L'archive ouverte pluridisciplinaire $\mathbf{H A L}$, est destinée au dépôt et à la diffusion de documents scientifiques de niveau recherche, publiés ou non, émanant des établissements d'enseignement et de recherche français ou étrangers, des laboratoires publics ou privés. 


\title{
Early and Adult Social Environments Shape Sex-Specific Actuarial Senescence Patterns in a Cooperative Breeder
}

\author{
Vérane Berger, ${ }^{1,2, *}$ Jean-François Lemaître, ${ }^{1}$ Dominique Allainé, ${ }^{1}$ Jean-Michel Gaillard, \\ and Aurélie Cohas ${ }^{1}$
}

1. Université de Lyon, F-69000, Lyon, Université Lyon 1, Centre National de la Recherche Scientifique, Unité Mixte de Recherche 5558, Laboratoire de Biométrie et Biologie Évolutive, F-69622, Villeurbanne, France; 2. Section of Ecology, Department of Biology, University of Turku, FI-20014 Turku, Finland

Submitted October 28, 2017; Accepted May 2, 2018; Electronically published August 23, 2018

Online enhancements: appendixes. Dryad data: http://dx.doi.org/10.5061/dryad.3cm38jd.

\begin{abstract}
AвSTRACT: Sociality modulates life-history traits through changes in resource allocation to fitness-related traits. However, how social factors at different stages of the life cycle modulate senescence remains poorly understood. To address this question, we assessed the influence of social environment in both early life and adulthood on actuarial senescence in the Alpine marmot, a cooperative breeder. The influence of helpers on actuarial senescence strongly differed depending on when help was provided and on the sex of the dominant. Being helped when adult slowed down senescence in both sexes. However, the effect of the presence of helpers during the year of birth of a dominant was sex specific. Among dominants helped during adulthood, females born in the presence of helpers senesced slower, whereas males senesced faster. Among dominants without helpers during adulthood, females with helpers at birth senesced faster. Social environment modulates senescence but acts differently between sexes and life stages.
\end{abstract}

Keywords: Alpine marmot, dominance, life history, mammal, monogamy, senescence.

\section{Introduction}

Evolutionary theories of actuarial senescence (i.e., the decline in age-specific survival with increasing age; henceforth, senescence) postulate that natural selection is strongest in early life, so that greater early investment in growth or reproduction should be favored even at the cost of faster actuarial senescence (Williams 1957; Hamilton 1966). Any life-history tactic or lifestyle (i.e., the covariation between ecological, physiological, and behavioral traits defining the way a species is living; see, e.g., Sibly and Brown 2007) that decreases allocation to growth or reproduction during early life should slow down senescence through increased allocation to repair at the

\footnotetext{
* Corresponding author; email: verane.berger@orange.fr. ORCIDs: Berger, http://dx.doi.org/0000-0002-2153-0719.

Am. Nat. 2018. Vol. 192, pp. 525-536. (C) 2018 by The University of Chicago. 0003-0147/2018/19204-58040\$15.00. All rights reserved.

DOI: $10.1086 / 699513$
}

cell level, as predicted by the disposable soma theory (Kirkwood and Rose 1991; Kirkwood 2017). Factors reducing allocation to growth or reproduction early in life are increasingly reported to slow down the rate of senescence, which often results in longer longevity in vertebrates (e.g., Nussey et al. 2007; Lemaître et al. 2015).

Recent theoretical studies suggest that kin selection also shapes actuarial senescence by modulating the allocation to growth during early life and to reproduction later on (Bourke 2007; Lee 2008). Eusocial and cooperatively breeding species are characterized by highly social groups composed of a breeding pair of dominants assisted by other individuals (often related to the dominants) called helpers. In such species, helpers are expected to reduce the costs associated with growth for the dominant's progeny as well as the costs of reproduction for the dominant itself (i.e., load-lightening hypothesis; Crick 1992). Consistent with the disposable soma theory (Kirkwood and Rose 1991), the energy saved from help received during reproduction could be reallocated to the maintenance of the organism, which should slow down senescence in breeding individuals.

Indeed, the eusocial naked mole rat (Heterocephalus glaber) and eusocial ants live 108 times longer than similar-sized mice (Andziak et al. 2005) and solitary ants (Keller and Genoud 1997), respectively. Similarly, cooperatively breeding birds outlive like-sized solitary birds twofold (Wasser and Sherman 2010). Cooperatively breeding vertebrates have a life-history tactic toward the slow end of the slow-fast continuum. This tactic involves a covariation between delayed and reduced early growth, delayed maturity (Blumstein and Armitage 1998), low fecundity, high adult survival, and delayed and slow senescence (Gaillard et al. 2016). However, it has never been investigated whether longevity in highly social species is simply a consequence of living on the slow end of the continuum (as suggested in Møller 2006).

Cooperative breeders offer ideal models to test whether sociality leads to delayed and slow senescence. They are or- 
ganized in highly social groups typically composed of a dominant breeding pair assisted by helpers that provide alloparental care and delay their own reproduction (Koenig et al. 1992). In early life, pups benefiting from help may save energy for growth and maintenance and consequently survive better (Jennions and Macdonald 1994; Cockburn 1998). Later in life, helpers may reduce the energy allocated by dominants to reproductive effort (Crick 1992). This saved energy can be reallocated to the maintenance of cellular and physiological functions, thereby delaying the onset and slowing down of senescence (Kirkwood and Rose 1991).

However, the expected benefit of helping in terms of slower senescence might be counterbalanced by increased competition within social groups. Cooperatively breeding species often show strong intrasexual competition (Hauber and Lacey 2005; Clutton-Brock et al. 2006). Such competition negatively affects body mass, survival, or reproductive success (Sharp and Clutton-Brock 2011). In Alpine marmots (Marmota marmota), a dominant is at greater risk of losing its tenure when the number of sexually mature same-sex subordinates increases (Lardy et al. 2012, 2013). In the cooperative meerkat (Suricata suricatta), intrasexual competition at birth leads to fasten reproductive senescence (Sharp and Clutton-Brock 2011).

In mammals, there is no known link between the number of helpers early in life and subsequent reproductive senescence (Sharp and Clutton-Brock 2010; Stahler et al. 2013). Previous studies have, however, reported that the number of helpers in early life extends reproductive life span in wolves (Canis rufus; Sparkman et al. 2011) and dominant female longevity in marmots (Berger et al. 2015). To the best of our knowledge, only two empirical studies on superb fairy-wrens (Malurus cyaneus; Cockburn et al. 2008) and Seychelles warblers (Acrocephalus sechellensis; Hammers et al. 2013) have tested for an effect of the social environment on the rate of senescence. Neither detected a relationship (Cockburn et al. 2008; Hammers et al. 2013). However, these studies focused on only the effect of helpers at birth (Hammers et al. 2013) or in adulthood (Cockburn et al. 2008). Neither study looked for possible interactive effects between the social environments at birth and in adulthood. Studying the interactive effect of social environment at different life stages in both sexes is crucial to provide an overview of the potentially complex effects of social environment on senescence (Bourke 2007; Lee 2008).

We took advantage of detailed, individual-based longitudinal monitoring of Alpine marmots to study the effects of social factors on senescence. The Alpine marmot is a longlived cooperatively breeding rodent living in family groups. Family groups typically include a dominant pair (living up to 16 years), subordinates related to at least one of the two dominants, and pups of the year (Perrin et al. 1993). Subordinates delay dispersal and forgo their own reproduction be- yond sexual maturity (Arnold 1990; Cohas et al. 2006). Only subordinate males help, providing alloparental care in the form of thermoregulation during hibernation (Arnold 1993; Allainé 2000; Allainé and Theuriau 2004). We tested the interaction between the number of helpers in the year of birth (hereafter, helpers at birth) and the presence of helpers during adulthood (hereafter, helpers in adulthood) on senescence in dominant Alpine marmots of both sexes while controlling for individual heterogeneity. We previously showed that early and adult social environments (measured as the number of helpers) independently lead to increase longevity of dominant females (Berger et al. 2015). We also detected evidence of senescence starting at 6 years of age in dominant marmots without any sex differences (Berger et al. 2016). We expect that the number and presence of helpers at birth and in adulthood delays and slows down senescence in dominant breeders and that this effect is similar in both sexes.

\section{Material and Methods}

\section{Study Species}

Alpine marmots are cooperatively breeding rodents living in family groups. Family groups typically include two to 16 individuals: a dominant pair, sexually mature adult subordinates (from 2 years of age onward), immature subordinates (between 1 and 2 years of age) related to at least one of the two dominants, and pups of the year (Perrin et al. 1993). All family members share the same territory that is mainly defended by the dominant pair.

The status of dominance is established for several years until the dominant is evicted by another individual or dies (Lardy et al. 2011). Most often, a dominant dies mostly during hibernation or when its territory is taken over. A takeover leads to either immediate death through combat or eviction of the former dominant. Forced to hibernate alone, evicted dominants have a $<2 \%$ chance to survive (Stephens et al. 2002); in 27 years of fieldwork, we have seen only two evicted dominants survive and reach dominance in another territory. Reproduction is highly skewed toward the dominant pair (Cohas et al. 2006). The reproduction of subordinates is inhibited by the same-sex dominant through aggressive behavior (Arnold and Dittami 1997; Hackländer et al. 2003). Reproductive suppression is often not complete in subordinate males, which can sometimes sire extra-pair young, while subordinate females experience complete reproductive suppression (Cohas et al. 2006). Dominant marmots mate during the 15 days following emergence from hibernation (i.e., from early to late April). After 30 days of gestation, dominant females give birth to the sole litter of the year (one to seven pups, median of 3.5). The altricial offspring stay in the natal burrow for 40 days. Once weaned, they emerge aboveground between mid-June and mid-July. At sexual maturity (i.e., 2 years 
of age), either an individual can stay as a subordinate in its natal group by delaying dispersal for one or several years or it can attempt to become dominant by either inheriting the dominance status in its natal group or dispersing to gain dominance in another territory. An individual never joins another family group as a subordinate.

When subordinates delay dispersal and forgo their own reproduction beyond sexual maturity (Arnold 1990; Cohas et al. 2006), they help by providing alloparental care (Allainé 2000). Although subordinates of both sexes use antipredator alarm calls to warn other family members, only subordinate males are effective helpers (Arnold 1993; Allainé and Theuriau 2004). All group members hibernate together from midOctober to early April. Hibernation is a cyclic process involving a succession of hypothermia and euthermia phases (Arnold 1990). Family members do not have the same length and rhythm of hibernation, and at each cycle, subordinate males wake up earlier and have longer euthermic periods than other family members, thus warming the burrow (Arnold 1988). Consequently, the number of subordinate males in a family group increases the probability of offspring to survive their first hibernation through thermal benefits of synchronized arousals and active warming. In turn, the number of subordinate males leads to an increase of the lifetime reproductive success of the dominant marmots (Lardy et al. 2015). On the other hand, the number of subordinate females has no or even a slight negative effect on pup survival (Arnold 1993; Allainé and Theuriau 2004).

\section{Field Procedures}

From 1990 to 2014, we used both capture-mark-recapture methods and direct observations to monitor a wild population of Alpine marmots located in Grande Sassière nature reserve (2,340 m asl, French Alps, $\left.45^{\circ} 29^{\prime} \mathrm{N}, 6^{\circ} 59^{\prime} \mathrm{E}\right)$. We captured marmots from 24 territories every year between midApril and mid-July using two-door live traps baited with dandelions (Taraxacum densleonis). We placed traps near the entrances of the main burrows to assign each captured individual to its family group. Once captured, we anesthetized individuals with Zolétil $100\left(0.1 \mathrm{~mL} \mathrm{~kg}^{-1}\right)$ and sexed them. We confirmed their social status through examination of the scrotum (males) or teats (females). We marked all individuals using a transponder and a numbered metal ear tag placed on the right ear of females and on the left ear of males for permanent individual recognition. We placed an additional colored plastic ear tag on the opposite ear of dominant individuals. Through daily observations, we further quantified the number of individuals of each sex and age class (i.e., offspring of the year, yearling and adult) for each family group, and we used scent marking behavior to confirm the identity of the dominant pair (Cohas et al. 2008).

\section{Age}

We measured age (in years) from birth to death for all knownaged dominant marmots (i.e., marmots that were marked as pups or yearlings) that died during the study (34 females, 36 males). Moreover, 36 known-aged dominant marmots (18 females, 18 males) were still alive and were censored in 2014. We assigned the age of 0 to all pups. Since we included only individuals with known longevity or with an exact age at censoring in the analyses, imperfect detection (sensu Gimenez et al. 2008) was not an issue in survival analyses.

\section{Social Environment}

For each dominant marmot, we measured early social environment by the number of subordinate males present in the year of its birth (three classes of helpers at birth: zero, one, and two or more) in its natal family group (21 females and 25 males without helpers at birth, seven females and 12 males with a single helper at birth, 24 females and 17 males with two or more helpers at birth). The number of helpers at birth was reduced to three categories because it rarely exceeded three, and previous studies showed that juvenile survival is not increased beyond two helpers at birth (Farand et al. 2002; Allainé and Theuriau 2004).

To measure the social environment experienced during adulthood, we recorded whether dominant marmots ever had at least one subordinate male over their dominance tenure length ( 13 females and 15 males without helpers in adulthood, 39 females and 39 males with helpers in adulthood). Because of fieldwork limitations, we could not accurately record the number of helpers every year during the entire life of all individuals, and the likelihood of having only partial social history for a given individual increased with group size and longevity. Hence, we could safely and accurately record only the presence/absence of adult helpers during adult life for all individuals independently of their age.

The number of helpers at birth was independent of the presence of helpers in adulthood $\left(\chi^{2}=2.15, \mathrm{df}=2, P=.34\right)$. The repeatability of the number of helpers during adulthood was equal to $0.26 \pm 0.07$ (see app. F for details; apps. A-G are available online), a value consistent with analyses of social behaviors (reviewed in Bell et al. 2009).

\section{Assessing the Influence of Early and Adult Social Environments on Senescence}

We studied age-related decreases in annual survival of Alpine marmots monitored individually throughout their entire lives. We recorded the observed longevity (i.e., time to death) of each dominant (306 and 281 years times individuals for females and males, respectively), or the survival time 
for individuals that were still alive when the monitoring ended and were therefore censored (134 and 123 years times individuals for females and males, respectively).

We modeled survival as a function of time to death using accelerated failure time (AFT) frailty models fitted with the survreg function in the R survival package (Therneau 2014) to test whether helpers early in life and at adulthood slow down the rate of senescence in dominant Alpine marmots of both sexes. The survival model using the survreg function is based on the number of observations (i.e., year times individuals) and not on the number of individuals. Our sample size thus comprised 440 observations for females and $404 \mathrm{ob}-$ servations for males. AFT models are based on cumulative survival curves (i.e., $l_{x}$ curves), and they allow getting a simple mathematical function of survival, which is not possible to obtain using nonparametric models. The outcomes of failure time models do not correspond to mortality ratios but express the effect of covariates on time to death (Therneau 2014). These models also control for the potential confounding effect of individual heterogeneity, as senescence can be masked at the population level by among-individual variation because of selective disappearance (van de Pol and Verhulst 2006). The response variable was the proportion of individuals surviving to each age, which can be directly obtained from the distribution of individual longevities.

To investigate the influence of social environments on senescence, we first pooled both sexes within a single analysis. Our statistical procedure included four steps. First, we assessed whether the Weibull survival function best described the data by comparing model fit using the Akaike information criterion (AIC; using Gompertz, Gaussian, exponential, extreme, or logistic functions as alternatives). For all analyses, a Weibull distribution best fitted the data (table A1; fig. C1; tables A1, B1, B2, E1, G1 and figs. C1, D1 are available online). Thus, the proportion of individuals surviving to each age $x$ was modeled as $l_{x}=\exp \left(-(x / \alpha)^{\beta}\right)$, where $\alpha$ is the scale parameter and $\beta$ is the shape parameter of the Weibull function. Although the two-parameter Weibull models constrain mortality to be null from the first age to the next (e.g., Gaillard et al. 2004), marmots never reach dominance before 2 years of age, meaning that dominant individuals could not have died before 2 years of age. The Weibull model using survreg can be interpreted as both proportional hazard $(\mathrm{PH})$ and AFT models. The PH models are based on the hazard function and give information on the ratio of mortality rate between the different modalities of a given factor. In Weibull AFT models (see table 1), the exponential of effect sizes $\left(\exp \left(\alpha_{\mathrm{AFT}}\right)\right)$ are interpreted biologically in terms of acceleration factor of time to death. From the coefficients obtained with Weibull AFT models, it is possible to calculate the hazard ratios $\left(\exp \left(\alpha_{\mathrm{PH}}\right)\right)$ given by Weibull $\mathrm{PH}$ models, assuming a constant shape factor $(\beta)$. The link between $\alpha_{\mathrm{AFT}}$ and $\alpha_{\mathrm{PH}}$ is given by the formula $\alpha_{\mathrm{PH}}=-\alpha_{\mathrm{AFT}} \beta$
(Kleinbaum and Klein 2012). Shape parameter indicates senescence when its value is greater than the value for constant mortality rate with age. Second, we assessed the effects of early and adult social factors on cumulative survival by including the number of helpers at birth, the presence of helpers in adulthood, the sex of the individual, as well as their two-way and three-way interactions for the analyses in which sexes were pooled. Once the full models including all potential additive and interactive effects had been built, we removed the non-statistically significant terms of a given order all at once until obtaining the minimal model. Third, to account for potential individual heterogeneity in mortality risk, we included a distribution of individual frailty (sensu Vaupel et al. 1979) by entering the individual identity as a gamma-distributed random effect, using the function frailty (Therneau 2014). Frailty was never statistically significant (table B1), which indicates a negligible individual heterogeneity in the mortality risk. Thus, we did not report models including individual heterogeneity in senescence, but we checked that results remained unchanged when including individual heterogeneity (table B2). Fourth, the model fit was evaluated by graphically comparing empirical Kaplan-Meier survival curves and predicted survival curves generated from the AFT model (fig. C1).

We tested for the three-way interaction (sex $x$ helpers at birth $\times$ helpers in adulthood) on senescence with pooled sexes using both a likelihood ratio test - comparing the threeway interaction model (sex $\times$ helpers at birth $\times$ helpers in adulthood) with the two-way interaction models (sex $x$ helpers at birth + sex $\times$ helpers in adulthood + helpers at birth $\times$ helpers in adulthood) — and using a model selection based on AIC (table G1). The sex of the dominant marmots modified the influence of both social environments, and thus the three-way interaction (sex $\times$ helpers at birth $\times$ helpers in adulthood) was statistically significant (see "Results"; table 1). We therefore replicated the four-step procedure described above with each sex considered separately to avoid the difficulty of providing a biological interpretation of a threeway interaction (e.g., for a similar procedure, see Festa-Bianchet et al. 1998). We included an interactive effect between helpers on senescence in each of the two sexes. The effect sizes are reported in table 1. In "Results," we report estimates of time to death with their associated $95 \%$ confidence intervals (CIs) and the corresponding hazard ratios given in table E1. We represented mortality rate $\left(m_{x}=1-\left(l_{x+1} / l_{x}\right)\right)$ as a function of age (fig. 1), and survival curves are given in fig. D1.

To measure senescence explicitly for each category of individuals, we defined a set of metrics describing senescence and longevity. From the estimations of the Weibull model, we defined the onset of senescence as the age at which the acceleration of the increase in the proportion of dying individuals was the strongest. This age corresponds to the earlier age at which the second derivative of the cumulative survival 
Table 1: Effect of number of helpers at birth and in adulthood on cumulative age-specific survival of Alpine marmots monitored in Grande Sassière nature reserve (1990-2014)

\begin{tabular}{|c|c|c|c|c|}
\hline & Effect size & SE & $Z$ & $P$ \\
\hline \multicolumn{5}{|l|}{ All dominant: } \\
\hline Intercept & 2.18 & .09 & 23.70 & $<.001$ \\
\hline Sun exposure of territory at birth (south) & -.14 & .08 & -1.67 & .09 \\
\hline Sun exposure of territory in adulthood (south) & .25 & .08 & 3.26 & $<.001$ \\
\hline Helpers at birth (1) & -.17 & .18 & -.94 & .35 \\
\hline Helpers at birth $(2+)$ & .38 & .12 & -3.21 & $<.01$ \\
\hline Helpers in adulthood & .19 & .09 & 2.05 & .04 \\
\hline Sex & -.41 & .14 & -2.98 & $<.01$ \\
\hline Sun exposure of territory at birth: sex & .35 & .10 & 3.41 & $<.001$ \\
\hline Sun exposure of territory in adulthood: sex & -.30 & .10 & -3.10 & $<.01$ \\
\hline Helpers at birth (1): sex & .17 & .21 & .79 & .43 \\
\hline Helpers at birth $(2+)$ : sex & .48 & .18 & 2.57 & .01 \\
\hline Helpers in adulthood:sex & .51 & .14 & 3.64 & $<.001$ \\
\hline Helpers in adulthood:helpers at birth (1) & .18 & .19 & .92 & .36 \\
\hline Helpers in adulthood: helpers at birth $(2+)$ & .65 & .14 & 4.79 & $<.001$ \\
\hline Helpers in adulthood:helpers at birth (1): sex & -.64 & .25 & -2.57 & .01 \\
\hline Helpers in adulthood:helpers at birth $(2+)$ : sex & -.98 & .21 & -4.72 & $<.001$ \\
\hline $\log (\text { scale })^{\mathrm{a}}$ & -1.88 & .08 & -23.95 & $<.001$ \\
\hline \multicolumn{5}{|l|}{ Dominant female: } \\
\hline Intercept & 2.15 & .10 & 22.46 & $<.001$ \\
\hline Sun exposure of territory at adulthood & .16 & .06 & 2.66 & $<.01$ \\
\hline Helpers at birth (1) & -.13 & .19 & -.70 & .48 \\
\hline Helpers at birth $(2+)$ & -.38 & .13 & -3.04 & $<.01$ \\
\hline Helpers in adulthood & .22 & .10 & 2.22 & .03 \\
\hline Helpers in adulthood:helpers at birth (1) & .18 & .21 & .86 & .39 \\
\hline Helpers in adulthood: helpers at birth $(2+)$ & .64 & .15 & 4.35 & $<.001$ \\
\hline $\log (\text { scale })^{\mathrm{b}}$ & -1.81 & .11 & -15.92 & $<.001$ \\
\hline \multicolumn{5}{|l|}{ Dominant male: } \\
\hline Intercept & 1.72 & .08 & 20.21 & $<.001$ \\
\hline Sun exposure of territory at birth & .20 & .06 & 3.63 & $<.001$ \\
\hline Helpers at birth (1) & .02 & .11 & .17 & .86 \\
\hline Helpers at birth $(2+)$ & .12 & .13 & .90 & .36 \\
\hline Helpers in adulthood & .72 & .09 & 7.73 & $<.001$ \\
\hline Helpers in adulthood:helpers at birth (1) & -.49 & .14 & -3.37 & $<.001$ \\
\hline Helpers in adulthood: helpers at birth $(2+)$ & -.35 & .15 & -2.35 & .02 \\
\hline $\log (\text { scale })^{c}$ & -1.93 & .11 & -17.88 & $<.001$ \\
\hline
\end{tabular}

Note: Sex indicates males. Shape parameter $(\beta)$ is equal to $1 /$ scale given by the function survreg from the survival package.

a $\beta=1 / \exp (\log ($ scale $))=6.55$.

${ }^{\mathrm{b}} \beta=1 / \exp (\log ($ scale $))=6.08$.

${ }^{c} \beta=1 / \exp (\log ($ scale $))=6.87$.

function estimated from the model reaches an extremum. We estimated the rate of senescence using two different ways. First, we measured the survival slope between the predicted ages where $50 \%\left(l_{x}=0.5\right)$ and $10 \%\left(l_{x}=0.1\right)$ of dominants are still alive in the population (see Lemaitre and Gaillard 2013). Second, we calculated Ricklefs and Scheuerlein's (2002) Weibull senescence rate, $\omega=\left(\beta / \alpha^{\beta}\right)^{(1 / \beta)}$, with $\alpha$ and $\beta$ corresponding to the scale and the shape parameters of the Weibull curves obtained from the survreg function. A small $\omega$ corresponds to a slow rate of senescence.

\section{Ecological Confounding Variables}

Territory quality might influence both the presence of helpers and senescence. In particular, sun exposure affects snow cover duration (Sharma et al. 2014), which in turn is a major factor determining plant phenology and biomass at a given altitude in mountain ecosystems (Inouye 2008). South-facing territories (where snow melts relatively early) are therefore of better quality than the north-facing or valley territories. As a result, both body mass at emergence and postweaning growth 

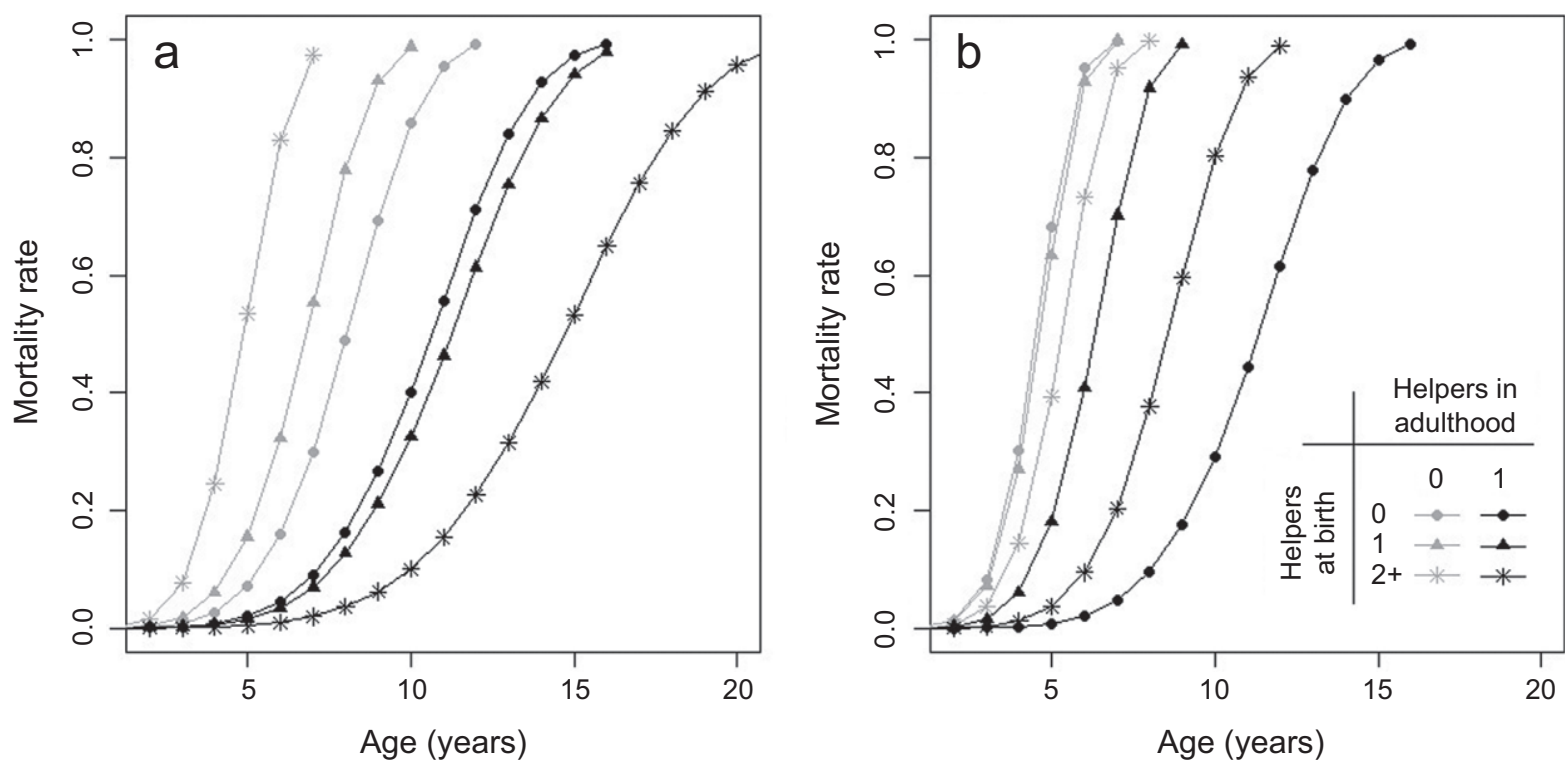

Figure 1: Effects of helpers at birth and in adulthood on the annual mortality rate of dominant female $(N=440$ observations; $a)$ and male $(N=404$ observations; $b)$ Alpine marmots. Symbols represent the predicted mortality at each age, obtained from the selected Weibull models including an interaction between helpers at birth and helpers in adulthood, with the territories at birth and in adulthood set to south. Circles, triangles, and asterisks correspond to the absence and presence of a single helper and of two or more helpers at birth, respectively. Gray and black symbols correspond to the absence and presence of helpers in adulthood, respectively.

rate are higher in south-facing than in valley and north-facing territories (Allainé et al. 1998). Therefore, we tested for additive and all interactive effects (up to the three-way interactions in the sex-pooled analyses) of the quality of the territory at birth and in adulthood (south vs. north/valley) in all analyses, and we kept these effects in the models whenever they were statistically significant. Data are deposited in the Dryad Digital Repository: http://dx.doi.org/10.5061/dryad.3cm38jd (Berger et al. 2018).

\section{Results \\ Ecological Confounding Variables}

Females occupying south-facing territories at adulthood lived 1.17 times longer $(95 \% \mathrm{CI}=1.04-1.33, z=2.66, P<.01)$ than dominant females established on valley or north-facing territories, and this effect occurred whatever their social environment at birth or later on. Males born in south-facing territories lived 1.22 times longer (95\% CI $=1.09-1.37, z=$ 3.62, $P<.001)$ than dominant males born in valley or north-facing territories. This territory effect occurred whatever the social environment of males at birth or in adulthood.

\section{Impact of Early and Adult Social Environment on Senescence}

The influence of helpers on senescence of Alpine marmots strongly differed in relation to the timing of the help (i.e., at birth vs. in adulthood) and between sexes (likelihood ratio test: $\chi^{2}=18.40, \mathrm{df}=2, P<.001$; table 1 ; fig. 1 ; for the AIC model selection, see table G1). As previously reported in the studied population, annual mortality rates increased with age in both sexes, and thus both sexes senesced. This is indicated by the shape parameters of the Weibull model of 6.87 (95\% CI $=5.58-8.50, z=15.92, P<.001)$ and 6.08 (95\% CI $=4.86-7.59, z=17.88, P<.001)$ for males and females, respectively (fig. 1). Indeed, both shape parameters were far $>1$ and thus indicated senescence. We did not detect any sex differences in the shape parameter.

In females, the number of helpers at birth and in adulthood had strong interactive effects (two-way interaction: $\chi^{2}=12.46$, df $=2, P=.002$; table 1 ; fig. $1 a$ ). Females with helpers during adulthood consistently displayed a slower rate of senescence (table 2). However, even though having helpers in adulthood is beneficial in terms of the slower rate of female senescence, the magnitude of this slowdown in senescence was modulated by the number of helpers that dominant females had at birth (fig. 1a). The life span of dominant females with one or zero helpers at birth was, respectively, 81\% (95\% CI $=68-95, z=-2.60, P=.009$ ) and $77 \%$ (95\% CI $=66-90, z=-3.45, P<.001)$ that of females with two or more helpers at birth (table 1). In the presence of helpers in adulthood, females senesced slower when having benefited from two or more helpers at birth $\left(\omega_{2+}=0.512\right)$ compared with one $\left(\omega_{1}=0.556\right)$ or zero $\left(\omega_{0}=0.568\right)$ helpers (table 2$)$. Females with helpers in adult- 
Table 2: Characterization of senescence parameters of predicted survival curves for dominant female and male Alpine marmots

\begin{tabular}{|c|c|c|c|c|c|c|}
\hline \multirow[b]{2}{*}{ Helpers at birth } & \multicolumn{3}{|c|}{ Absence of helpers in adulthood } & \multicolumn{3}{|c|}{ Presence of helpers in adulthood } \\
\hline & 0 & 1 & $2+$ & 0 & 1 & $2+$ \\
\hline \multicolumn{7}{|l|}{ Dominant female: } \\
\hline Onset of senescence & 5.99 & 5.14 & 3.79 & 7.69 & 8.11 & 10.19 \\
\hline Range & 5.54 to 6.44 & 3.767 to 6.87 & 2.96 to 4.77 & 6.37 to 9.20 & 4.23 to 14.71 & 6.23 to 16.21 \\
\hline Rate $(50 \%-10 \%)$ & -.24 & -.272 & -.35 & -.19 & -.18 & -.15 \\
\hline Range & -.30 to -.19 & -.41 to -.18 & -.49 to -.25 & -.26 to -.14 & -.37 to -.01 & -.27 to -.08 \\
\hline$\omega$ & .63 & .67 & .76 & .57 & .56 & .51 \\
\hline \multicolumn{7}{|l|}{ Dominant male: } \\
\hline Onset of senescence & 3.69 & 3.79 & 4.30 & 8.61 & 5.06 & 6.69 \\
\hline Range & 3.40 to 3.98 & 3.01 to 4.68 & 3.35 to 5.41 & 7.21 to 10.21 & 3.00 to 8.14 & 3.97 to 10.84 \\
\hline Rate $(50 \%-10 \%)$ & -.41 & -.41 & -.42 & -.20 & -.32 & -.25 \\
\hline Range & -.51 to -.34 & -.55 to -.30 & -.50 to -.26 & -.27 to -.15 & -.55 to -.18 & -.45 to -.14 \\
\hline$\omega$ & .77 & .76 & .72 & .54 & .67 & .63 \\
\hline
\end{tabular}

Note: Predicted curves were obtained from the selected Weibull model including an interaction between helpers at birth and in adulthood. We characterized the onset of senescence in years as the age at which the acceleration of the increase in the proportion of dying individuals is maximal. We defined Ricklefs's $\omega$ rate of senescence (for details, see "Methods"). Another metric of the rate of senescence $(50 \%-10 \%)$ is defined as the survival slope between the ages where $50 \%\left(l_{x}=0.5\right)$ and $10 \%\left(l_{x}=0.1\right)$ of dominants.

hood had a longevity of 11,12 , and 16 years when they had zero, one, and two or more helpers at birth, respectively.

In contrast, in the absence of helpers in adulthood, the life span of females having two or more helpers at birth was $68 \%$ (95\% CI $=53-88, z=-3.04, P=.002)$ that of females without helpers at birth (table 1 ) and increased senescence $\left(\omega_{2+}=0.760\right.$ vs. $\omega_{0}=0.626$; table 2$)$. However, we found no difference in life span (table 1) or the rate of senescence (table 2) between females having two or more versus one helper at birth (factor of 0.78 ; $95 \% \mathrm{CI}=0.53-1.15, z=$ $\left.-1.28, P=.20 ; \omega_{2+}=0.760, \omega_{1}=0.666\right)$ or between females with one versus zero helpers at birth (factor of 0.87 ; $95 \% \mathrm{CI}=0.60-1.28, z=-0.705, P=.48 ; \omega_{1}=0.666$, $\left.\omega_{0}=0.626\right)$. Females with zero, one, and two or more helpers at birth lived for a maximum of 8,6 , and 6 years of age, respectively.

In males, we also detected interactive effects between the number of helpers at birth and in adulthood (two-way interaction: $\chi^{2}=8.92, \mathrm{df}=2, P=.01$; table 1 ; fig. $1 b$ ). Like females, males with helpers in adulthood displayed a markedly slower rate of senescence (table 2 ), and again the number of helpers that males had at birth modulated the magnitude of this slowdown (fig. 1b). However, unlike females, males with helpers in adulthood suffered from the presence of helpers at birth (fig. 1b). Males without helpers at birth had the slowest rate of senescence (table 2), and their life span increased by a factor of 1.60 (95\% CI $=1.34-1.90$, $z=5.29, P<.001)$ or $1.25(95 \% \mathrm{CI}=1.10-1.42, z=$ $3.55, P \leq .001)$ compared with males with one and two or more helpers at birth, respectively (table 1 ). Moreover, males having two or more helpers at birth had their life span increase by a factor of 1.27 (95\% CI $=1.07-1.51, z=2.78$,
$P=.005)$ compared with males having one helper at birth (table 1), and they experienced a slower rate of senescence (table 2). Males with helpers in adulthood lived for a maximum of 14,8 , and 11 years when they had zero, one, and two or more helpers at birth, respectively.

Senescence in males that had no helpers in adulthood was not influenced by social environment at birth (fig. 1b). Males with one and two or more helpers at birth had a similar life span (i.e., factor of 1.02; 95\% CI $=0.81-1.27, z=0.17$, $P=.86$; factor of 1.13 ; $95 \% \mathrm{CI}=0.87-1.47, z=0.90$, $P=.37$ ) as males without any helper at birth (table 1), and all showed similar senescence rates (table 2). Males without any helpers in adulthood never lived beyond 5 years, regardless of the social environment they experienced at birth.

\section{Discussion}

Sociality has been suggested to modify life-history trade-offs and thus to affect senescence indirectly (Lee 2003; Bourke 2007). We found that social environments encountered both at birth and in adulthood shape senescence in a cooperatively breeding mammal. Moreover, we show that the effect of the social environments met at different life stages strongly differs and depends on sex. The effect of sociality on senescence is much more complex than expected under current lifehistory theory.

Our study provides clear evidence that the presence of helpers in adulthood slows down the rate of senescence in both sexes. This finding supports the load-lightening hypothesis (Crick 1992), in which dominants should benefit from helping by reducing their parental investment, thereby im- 
proving their survival and lifetime reproductive success. In Alpine marmots, increasing the number of helpers leads to not only improved juvenile survival (up to a point; Allainé and Theuriau 2004) but also improved longevity and lifetime reproductive success of dominants of both sexes (Berger et al. 2015; Lardy et al. 2015), and dominants' overwinter weight loss is reduced when they hibernate with helpers (Arnold 1990). The presence of helpers in adulthood is therefore likely to decrease the reproductive costs of dominants of both sexes. By reallocating the energy from reproduction to somatic maintenance, the presence of helpers could slow down senescence (this study). A positive effect of helpers on the survival and lifetime reproductive success of dominants resulting from load lightning has been reported in other cooperatively breeding birds and mammals (e.g., Khan and Walters 2002; Russell et al. 2007). In all these cooperative breeders, the presence of helpers is thus likely to delay and slow down senescence.

However, mechanisms through which helpers affect senescence in the two dominant sexes are likely to differ. Gestation and lactation are two major costs of reproduction (Clutton-Brock et al. 1989) for females during the active period, and they are both reduced in the presence of helpers. Males suffer from important overwinter body mass loss in the presence of pups (Ruf and Arnold 2000) because they wake up earlier and have longer euthermic periods during hibernation (Arnold 1988). The amount of energy expended by males during hibernation is a function of the number of helpers. As a consequence, hibernation could be highly costly in the absence of helpers and could potentially lead to a loss of dominance and ultimately to death (Arnold 1990; Allainé and Theuriau 2004). According to empirical knowledge on Alpine marmots, the effect of helping during adulthood is expected to act predominantly during the active season for dominant females and to slow down the rate of senescence by decreasing reproductive costs. In contrast, in dominant males, the helper effect during adulthood takes place during hibernation and is expected to slow down the rate senescence by decreasing thermoregulatory costs.

The effect of helpers at birth is complex because it combines sex-specific effects on senescence and unexpected interacting effects with the presence of helpers during adulthood in the Alpine marmot. Sex-specific effects of helpers at birth on life-history traits other than senescence are commonly reported in cooperative breeders (Sparkman et al. 2011; Paquet et al. 2015) and have long-term consequences. In red wolves, in the presence of helpers early in life, reproductive performance increases in females but is reduced in males (Sparkman et al. 2011). In sociable weavers (Philetairus socius), the presence of helpers increases female survival but decreases male survival especially in early life, and this opposite sex-specific effect is reduced late in life (Paquet et al. 2015). In dominant female Alpine marmots, being born in the presence of helpers may be beneficial in terms of slower senescence when these females also have helpers in adulthood but is detrimental in their absence. This opposite effect of the presence of helpers at birth on female senescence depending on the presence or absence of helpers in adulthood could correspond to a predictive adaptive response. This response could allow offspring born in a given social environment (i.e., with or without helpers at birth in marmot females) to adjust their physiology during their early development so that they will perform better during adulthood when they will meet the same conditions (Bateson et al. 2004). This kind of developmental adjustment to future environmental conditions has been recently defined as the external predictive adaptive response (Nettle et al. 2013). In female Alpine marmots, this response to the environment could set up during the first hibernation, a crucial stage in marmot life history. This response can occur only if the adult social environment is predictable, which is likely to be the case in Alpine marmot females, which inherit their natal territory at sexual maturity more often than males do (35\% of the dominant females vs. $15 \%$ of the dominant males; Lardy et al. 2012). Thus, by inheriting their natal territory, female dominants also inherit helpers already present in the territory. Although the mechanisms involved remain to be investigated, our study suggests that the variability of the social environments over the life course might offer the conditions required for adaptive responses to evolve in cooperative breeders, at least in females. So far, the search for external predictive adaptive responses has been generally restricted to vertebrates and to responses to ecological factors such as food, climate, or predation and does not provide any support to the external predictive adaptive responses (Hayward et al. 2013; Douhard et al. 2014). Our findings call for further sexspecific studies integrating sociality in this framework.

In males, the influence of the number of helpers at birth on senescence was markedly different. When males did not have helpers in adulthood, the presence of helpers at birth had no influence on senescence, whereas the presence of helpers at birth had a negative effect in males with helpers in adulthood. Male reproductive costs during hibernation are substantial in the absence of helpers in adulthood, which compromises any positive effect of the social environment early in life and leads to a faster senescence. Helpers in early life could impose long-term detrimental costs on survival because of a modulation of the early-late life trade-off favoring growth and reproductive performance over somatic maintenance in male pups, as reported in red wolves (Sparkman et al. 2011). However, intrasexual competition could also play a pivotal role in the early-late trade-off and thereby senescence. Indeed, intrasexual competition, common in cooperative breeding species (e.g., Clutton-Brock et al. 2006), is associated with senescence at later ages (Sharp and CluttonBrock 2011). In the specific case of hibernating species, such 
as the Alpine marmot, the trade-off between male allocation to sexual competition and somatic maintenance may be leveled off above a certain number of helpers at birth. Indeed, the ambient temperature in the hibernaculum rises with the number of helpers, thus reducing the physiological costs of hibernation (Arnold 1993). Higher temperatures lead to both lower overwinter mass loss and higher overwinter offspring survival (Arnold 1990; Grimm et al. 2003; Allainé and Theuriau 2004) and then to a decreased viability selection. In absence of helpers at birth, males are likely to face high viability selection caused by both high intrasexual competition between brothers of the same age and drastic hibernation conditions without helpers. High viability selection leads to only the most robust males surviving and therefore slows down senescence. With only one helper at birth, male pups face reduced costs of hibernation and lower competition with helpers, which leads to a decreased viability selection and thereby a faster senescence. With two or more helpers at birth, the intrasexual competition between male pups and helpers could counterbalance the benefits of social thermoregulation, leading to an intermediate magnitude of senescence. This may explain why senescence of males helped during adulthood was less for those born with at least two helpers than with only one helper. Overall, we suggest that the complex interaction between early and adult social environments observed in male marmots is likely to be the consequence of the interplay between life-history trade-offs, environmental conditions, and the ecology of hibernating cooperative breeding species. Although complex outcomes of competition and cooperation are plausible explanations, more investigation is needed before drawing any firm conclusion about the exact processes underlying the present findings.

Explaining these intriguing sex differences in senescence with or without helpers at birth is not straightforward. The absence of an external predictive adaptive response in males is difficult to explain and emphasizes that we still know very little about sex differences in such responses. However, two important features distinguish males from females early in life. First, male (but not female) pups compete with helpers. Although we do not yet have direct evidence of competition between male pups and helpers within a family group, previous results in our population provide evidence of competition between male littermates. Male juvenile survival decreases with an increasing number of brothers in the litter (Dupont et al. 2015). Moreover, males form coalitions that often involve brothers of successive litters when dispersing in search for a breeding vacancy, a tactic commonly used by other social mammalian species, such as lions (Panthera leo; Packer et al. 1991). When one male becomes the new dominant, its brothers soon become competitors that have to be evicted from the territory. Males born with relatively few brothers are more likely to disperse alone and pay a lower cost in terms of intrasexual competition than males dispersing with brothers. The presence of helpers at birth could therefore lead young male marmots to adopt a live fast, die young strategy (Vinogradov 1998; Bonduriansky et al. 2008). The costs of being raised with brothers or of searching for a new territory could be paid late in life by fastening senescence, in line with the predictions of the disposable soma theory (Kirkwood and Rose 1991). Second, the presence of an external predictive adaptive response in females but not males can be caused by physiological differences between sexes. Males and females show markedly different fat storage and metabolism mechanisms, as already shown in mammals (e.g., humans: Power and Schulkin 2008). In particular, fat storage for reproduction is mostly devoted to females (small mammals: Schulte-Hostedde et al. 2001; gray seals Halichoerus grypus: Beck et al. 2003). In Alpine marmots, the use of fat reserves is both sex and season specific (Körtner and Heldmaier 1995). Although it has not been shown yet, we can hypothesize that females should favor storing fat reserves for reproduction and hibernation, whereas males should mostly use fat storage for social thermoregulation during hibernation. The ontogeny of these tissues could be influenced differently by the early environment between the sexes and could remain sex specific later in life. The interplay between sex difference in lipolysis and thermogenesis mechanisms and early social environment could therefore explain the presence of external predictive adaptive response only in females.

From our correlative approach, we cannot exclude that a nonmeasured phenotypic or genetic factor could be responsible for the observed correlation. For example, robust individuals that live longer and age later and slower might have a higher probability of gaining helpers during their life than frail individuals. The presence of helpers might also indirectly influence senescence because of some hidden effect of other ecological factors, such as predation. However, in Alpine marmots, helpers' alarm calls benefit the whole population and not only their focal family group. Therefore, predation cannot explain the antagonistic effects of helpers we found on cumulative survival. Predation is thus unlikely to generate the effects of social environments we reported on senescence.

Our study shows how important the interplay between social factors and sex is for shaping senescence. Sex-specific effects of social environments at different life stages on aging are expected to be widespread. Testing this prediction in cooperative breeders other than Alpine marmots would improve our understanding of the effect of sociality on aging and of the potential role of kin selection in shaping aging patterns. Finally, one important challenge now is to quantify the costs of helping and reproduction and how these costs are modulated by social factors. Dissecting how sociality could influence costs of helping and reproduction would improve our understanding of how sociality during the life course influences senescence and longevity. 


\section{Acknowledgments}

We thank Daniel Bolnick, Dan Nussey, Andrew Bourke, and one anonymous reviewer for insightful and constructive comments on previous drafts of this work. We also thank all students involved in the trapping of marmots and Earthwatch for volunteers. We are grateful to Floriane Plard for her help in the use of the survival package; to Laurent Jacob for his help with the analysis of the Weibull function; to Mike Garratt for insightful comments; and to Simon Chapman, Kathryn A. Angell, and Herman B. Leonard for editing the language. Financial support was received from the Agence Nationale de la Recherche (project ANR-13-JSV7-0005 to A.C. and project ANR-15-CE32-0002-01 to J.-F.L.), the Centre National de la Recherche Scientifique, and Earthwatch Institute. The fieldwork conducted was undertaken after deliverance of permit AP n82010/121 by the Préfecture de la Savoie. A.C. is authorized for experimentation with animals (diploma n8R45GRETAF110). The protocol has been approved by the ethical committee of the University of Claude Bernard Lyon 1 (n8BH2012-92 V1).

Statement of authorship: A.C. and D.A. conceived the study; A.C., D.A., and V.B. contributed to the data collection; V.B. and A.C. performed the analyses; V.B., J.-F.L., D.A., J.-M.G., and A.C. wrote the manuscript; and all authors provided editorial advice and gave final approval for publication.

\section{Literature Cited}

Allainé, D. 2000. Sociality, mating system and reproductive skew in marmots: evidence and hypotheses. Behavioral Processes 51:2134.

Allainé, D., L. Graziani, and J. Coulon. 1998. Postweaning mass gain in juvenile alpine marmots Marmota marmota. Oecologia 113:370376.

Allainé, D., and F. Theuriau. 2004. Is there an optimal number of helpers in alpine marmot family groups? Behavioral Ecology 15:916924.

Andziak, B., T. P. O'Connor, and R. Buffenstein. 2005. Antioxidants do not explain the disparate longevity between mice and the longestliving rodent, the naked mole-rat. Mechanism of Ageing and Development 126:1206-1212.

Arnold, W. 1988. Social thermoregulation during hibernation in alpine marmots (Marmota marmota). Journal of Comparative Physiology B 158:151-156.

1990. The evolution of marmot sociality. II. Costs and benefits of joint hibernation. Behavioral Ecology and Sociobiology 27:239246.

1993. Social evolution in marmots and the adaptive value of joint hibernation. Verhandlungen der Deutschen Zoologischen Gesellschaft 86:79-93.

Arnold, W., and J. P. Dittami. 1997. Reproductive suppression in male alpine marmots. Animal Behaviour 53:53-66.

Bateson, P., D. Barker, T. Clutton-Brock, D. Deb, B. D'Udine, R. A. Foley, P. Gluckman, et al. 2004. Developmental plasticity and human health. Nature 430:419-421.
Beck, C. A., W. D. Bowen, and S. J. Iverson. 2003. Sex differences in the seasonal patterns of energy storage and expenditure in a phocid seal. Journal of Animal Ecology 72:280-291.

Bell, A. M., S. J. Hankison, and K. L. Laskowski. 2009. The repeatability of behaviour: a meta-analysis. Animal Behaviour 77:771-783.

Berger, V., J. F. Lemaître, D. Allainé, J. M. Gaillard, and A. Cohas. 2015. Early and adult social environments have independent effects on individual fitness in a social vertebrate. Proceedings of the Royal Society B 282:20151167.

- 2018. Data from: Early and adult social environments shape sex-specific actuarial senescence patterns in a cooperative breeder. American Naturalist, Dryad Digital Repository, https://dx.doi.org /10.5061/dryad.3cm38jd.

Berger, V., J. F. Lemaître, P. Dupont, D. Allainé, J. M. Gaillard, and A. Cohas. 2016. Age-specific survival in the socially monogamous alpine marmot (Marmota marmota): evidence of senescence. Journal of Mammalogy 97:992-1000.

Blumstein, D. T., and K. B. Armitage. 1998. Life history consequences of social complexity: a comparative study of ground-dwelling sciurids. Behavioral Ecology 9:8-19.

Bonduriansky, R., A. Maklakov, F. Zajitschek, and R. Brooks. 2008. Sexual selection, sexual conflict and the evolution of ageing and life span. Functional Ecology 22:443-453.

Bourke, A. F. G. 2007. Kin selection and the evolutionary theory of aging. Annual Review of Ecology, Evolution, and Systematics 38:103128.

Clutton-Brock, T. H., S. D. Albon, and F. E. Guinness. 1989. Fitness costs of gestation and lactation in wild mammals. Nature 337:260262.

Clutton-Brock, T. H., S. J. Hodge, G. Spong, A. F. Russell, N. R. Jordan, N. C. Bennett, L. L. Sharpe, and M. B. Manser. 2006. Intrasexual competition and sexual selection in cooperative mammals. Nature 444:1065-1068.

Cockburn, A. 1998. Evolution of helping behaviour in cooperatively breeding birds. Annual Review of Ecology, Evolution, and Systematics 29:141-177.

Cockburn, A., R. A. Sims, H. L. Osmond, D. J. Green, M. C. Double, and R. A. Mulder. 2008. Can we measure the benefits of help in cooperatively breeding birds: the case of superb fairy-wrens Malurus cyaneus? Journal of Animal Ecology 77:430-438.

Cohas, A., N. G. Yoccoz, C. Bonenfant, B. Goossens, C. Genton, M. Galan, B. Kempenaers, and D. Allainé. 2008. The genetic similarity between pair members influences the frequency of extrapair paternity in alpine marmots. Animal Behaviour 76:87-95.

Cohas, A., N. G. Yoccoz, A. Da Silva, B. Goossens, and D. Allainé. 2006. Extra-pair paternity in the monogamous alpine marmot (Marmota marmota): the roles of social setting and female mate choice. Behavioral Ecology and Sociobiology 55:597-605.

Crick, H. Q. P. 1992. Load-lightening in cooperatively breeding birds and the cost of reproduction. Ibis 134:56-61.

Douhard, M., F. Plard, J.-M. Gaillard, G. Capron, D. Delorme, F. Klein, P. Duncan, L. E. Loe, and C. Bonenfant. 2014. Fitness consequences of environmental conditions at different life stages in a long-lived vertebrate. Proceedings of the Royal Society B 281:20140276.

Dupont, P., R. Pradel, S. Lardy, D. Allainé, and A. Cohas. 2015. Litter sex composition influences dominance status of Alpine marmots (Marmota marmota). Oecologia 179:753-763.

Farand, E., D. Allainé, and J. Coulon. 2002. Variation in survival rates for the alpine marmot (Marmota marmota): effects of sex, age, year, and climatic factors. Canadian Journal of Zoology 80:342-349. 
Festa-Bianchet, M., J.-M. Gaillard, and J. T. Jorgenson. 1998. Mass- and density-dependent reproductive success and reproductive costs in a capital breeder. American Naturalist 52:367-379.

Gaillard, J.-M., J.-F. Lemaître, V. Berger, C. Bonenfant, S. Devillard, M. Douhard, M. Gamelon, F. Plard, and J.-D. Lebreton. 2016. Life histories, axes of variation in. Pages 312-323 in R. M. Kliman, ed. Encyclopedia of evolutionary biology. Vol. 2. Academic Press, Oxford.

Gaillard, J.-M., A. Viallefont, A. Loison, and M. Festa-Bianchet. 2004 Assessing senescence patterns in populations of large mammals. Animal Biodiversity and Conservation 27:47-58.

Gimenez, O., A. Viallefont, A. Charmantier, R. Pradel, E. Cam, C. R. Brown, M. D. Anderson, M. B. Brown, R. Covas, and J.-M. Gaillard. 2008. The risk of flawed inference in evolutionary studies when detectability is less than one. American Naturalist 172:441-448.

Grimm, V., N. Dorndorf, F. Frey-Roos, C. Wissel, T. Wyszomirski, and W. Arnold. 2003. Modelling the role of social behavior in the persistence of the Alpine marmot Marmota marmota. Oikos 102:124-136.

Hackländer, K., E. Mostl, and W. Arnold. 2003. Reproductive suppression in female Alpine marmots (Marmota marmota). Animal Behaviour 65:1133-1140.

Hamilton, W. D. 1966. The moulding of senescence by natural selection. Journal of Theoretical Biology 12:12-45.

Hammers, M., D. S. Richardson, T. Burke, and J. Komdeur. 2013. The impact of reproductive investment and early-life environmental conditions on senescence: support for the disposable soma hypothesis. Journal of Evolutionary Biology 26:1999-2007.

Hauber, M. E., and E. A. Lacey. 2005. Bateman's principle in cooperative breeding vertebrates: the effects of non-breeding alloparents on variability in female and male reproductive success. Integrative and Comparative Biology 45:903-914.

Hayward, A. D., I. J. Rickard, and V. Lummaa. 2013. Influence of earlylife nutrition on mortality and reproductive success during a subsequent famine in a preindustrial population. Proceedings of the National Academy of Sciences of the USA 110:13,886-13,891.

Inouye, D. W. 2008. Effects of climate change on phenology, frost damage, and floral abundance of montane wildflowers. Ecology 89:353362.

Jennions, M. D., and D. W. Macdonald. 1994. Cooperative breeding in mammals. Trends in Ecology and Evolution 9:89-93.

Keller, L., and M. Genoud. 1997. Extraordinary lifespans in ants: a test of evolutionary theories of ageing. Nature 389:958-960.

Khan, M. Z., and J. R. Walters. 2002. Effects of helpers on breeder survival in the red-cockaded woodpecker (Picoides borealis). Behavioral Ecology and Sociobiology 51:336-344.

Kirkwood, T. B. L. 2017. 2: the disposable soma theory. Pages 23-39 in R. P. Shefferson, O. R. Jones, and R. Salguero-Gómez, eds. Evolution of senescence in the tree of life. Cambridge University Press, Cambridge.

Kirkwood, T. B. L., and M. R. Rose. 1991. Evolution of senescence: late survival sacrificed for reproduction. Philosophical Transactions of the Royal Society B 332:15-24.

Kleinbaum, D. G., and M. Klein. 2012. Survival analysis: a self-learning text. Springer, Berlin.

Koenig, W. D., F. A. Pitelka, W. J. Carmen, R. L. Mumme, and M. T. Stanback. 1992. The evolution of delayed dispersal in cooperative breeders. Quarterly Review of Biology 67:111-150.

Körtner, G., and G. Heldmaier. 1995. Body weight cycles and energy balance in the alpine marmot (Marmota marmota). Physiological Zoology 68:149-163.
Lardy, S., D. Allainé, C. Bonenfant, and A. Cohas. 2015. Sex-specific determinants of fitness in a social mammal. Ecology 96:2947-2959.

Lardy, S., D. Allainé, and A. Cohas. 2013. Intrasexual competition and female dominance in a singular breeding mammal, the Alpine marmot. Animal Behaviour 86:1155-1163.

Lardy, S., A. Cohas, E. Desouhant, M. Tafani, and D. Allainé. 2012. Paternity and dominance loss in male breeders: the cost of helpers in a cooperatively breeding mammal. PLoS One 7:e29508.

Lardy, S., A. Cohas, I. Figueroa, and D. Allainé. 2011. Mate change in a socially monogamous mammal: evidences support the "forced divorce" hypothesis. Behavioral Ecology 22:120-125.

Lee, R. D. 2003. Rethinking the evolutionary theory of aging: transfers, not births, shape senescence in social species. Proceedings of the National Academy of Sciences of the USA 100:9637-9642.

2008. Sociality, selection, and survival: simulated evolution of mortality with intergenerational transfers and food sharing. Proceedings of the National Academy of Sciences of the USA 105:71247128 .

Lemaître, J. F., V. Berger, C. Bonenfant, M. Douhard, M. Gamelon, F. Plard, and J.-M. Gaillard. 2015. Early-late life trade-offs and the evolution of ageing in the wild. Proceedings of the Royal Society B 282:20150209.

Lemaître, J. F., and J. M. Gaillard. 2013. Male survival patterns do not depend on male allocation to sexual competition in large herbivores. Behavioral Ecology 24:421-428.

Møller, A. P. 2006. Sociality, age at first reproduction and senescence: comparative analyses of birds. Journal of Evolutionary Biology 19:682689.

Nettle, D., W. E. Frankenhuis, and I. J. Rickard. 2013. The evolution of predictive adaptive responses in human life history. Proceedings of the Royal Society B 280:20131343.

Nussey, D. H., L. E. Kruuk, A. Morris, and T. H. Clutton-Brock. 2007. Environmental conditions in early life influence ageing rates in a wild population of red deer. Current Biology 17:R1000-R1001.

Packer, C., D. A. Gilbert, A. E. Pusey, and S. J. O’Brieni. 1991. A molecular genetic analysis of kinship and cooperation in African lions. Nature 351:562-565.

Paquet, M., C. Doutrelant, B. J. Hatchwell, C. N. Spottiswoode, and R. Covas. 2015. Antagonistic effect of helpers on breeding male and female survival in a cooperatively breeding bird. Journal of Animal Ecology 84:1354-1362.

Perrin, C., J. Coulon, and M. Le Berre. 1993. Social behavior of alpine marmots (Marmota marmota): seasonal, group, and individual variability. Canadian Journal of Zoology 71:1945-1953.

Power, M. L., and J. Schulkin. 2008. Sex differences in fat storage, fat metabolism, and the health risks from obesity: possible evolutionary origins. British Journal of Nutrition 99:931-940.

Ricklefs, R. E., and A. Scheuerlein. 2002. Biological implications of the Weibull and Gompertz models of aging. Journals of Gerontology Series A: Biological Sciences and Medical Sciences 57:69-76.

Ruf, T., and W. Arnold. 2000. Mechanisms of social thermoregulation in hibernating alpine marmots (Marmota marmota). Pages 81-94 in G. Heldmaier and M. Klingenspor, eds. Life in the cold. Springer, Berlin.

Russell, A. F., N. E. Langmore, A. Cockburn, L. B. Astheimer, and R. M. Kilner. 2007. Reduced egg investment can conceal helper effects in cooperatively breeding birds. Science 317:941-944.

Schulte-Hostedde, A. I., J. S. Millar, and G. J. Hickling. 2001. Sexual dimorphism in body composition of small mammals. Canadian Journal of Zoology 79:1016-1020. 
Sharma, V., V. D. Mishra, and P. K. Joshi. 2014. Topographic controls on spatio-temporal snow cover distribution in Northwest Himalaya. International Journal of Remote Sensing 35:3036-3056.

Sharp, P. S., and T. H. Clutton-Brock. 2010. Reproductive senescence in a cooperatively breeding mammal. Journal of Animal Ecology 79:176-183.

2011. Competition, breeding success and ageing rates in female meerkats. Journal of Evolutionary Biology 24:1756-1762.

Sibly, R. M., and J. H. Brown. 2007. Effects of body size and lifestyle on evolution of mammal life histories. Proceedings of the National Academy of Sciences of the USA 104:17707-17712.

Sparkman, A. M., J. Adams, A. Beyer, T. D. Steury, L. Waits, and D. L. Murray. 2011. Helper effects on pup lifetime fitness in the cooperatively breeding red wolf (Canis rufus). Proceedings of the Royal Society B 278:1381-1389.

Stahler, D. R., D. R. MacNulty, R. K. Wayne, B. VonHoldt, and D. W. Smith. 2013. The adaptive value of morphological, behavioural and life-history traits in reproductive female wolves. Journal of Animal Ecology 82:222-234.

Stephens, P. A., F. Frey-Roos, W. Arnold, and W. J. Sutherland. 2002. Model complexity and population predictions. The alpine marmot as a case study. Journal of Animal Ecology 71:343-361.

Therneau, T. M. 2014. A package for survival analysis in S. R package version 2.37-7.

van de Pol, M., and S. Verhulst. 2006. Age-dependent traits: a new statistical model to separate within- and between-individual effects. American Naturalist 167:766-773.

Vaupel, J. W., K. G. Manton, and E. Stallard. 1979. The impact of heterogeneity in individual frailty on the dynamics of mortality. Demography 16:439-454.
Vinogradov, A. E. 1998. Male reproductive strategy and decreased longevity. Acta Biotheoretica 46:157-160.

Wasser, D. E., and P. W. Sherman. 2010. Avian longevities and their interpretation under evolutionary theories of senescence. Journal of Zoology 280:103-155.

Williams, G. C. 1957. Pleiotropy, natural selection, and the evolution of senescence. Evolution 11:398-411.

\section{References Cited Only in the Online Appendixes}

Burnham, K. P., and D. R. Anderson. 2002. Model selection and multimodel inference. Springer, New York.

Nakagawa, S., and H. Schielzeth. 2010. Repeatability for Gaussian and non-Gaussian data: a practical guide for biologists. Biological Reviews 85:935-956.

Stoffel, M. A., S. Nakagawa, and H. Schielzeth. 2017. rptR: repeatability estimation and variance decomposition by generalized linear mixed-effects models. Methods in Ecology and Evolution 8:16391644.

Therneau, T. M., and P. M. Grambsch. 2013. Modeling survival data: extending the Cox model. Springer, New York.

Vaupel, J. W., and A. I. Yashin. 1985. Heterogeneity's ruses: some surprising effects of selection on population dynamics. American Statistician 39:176-185.

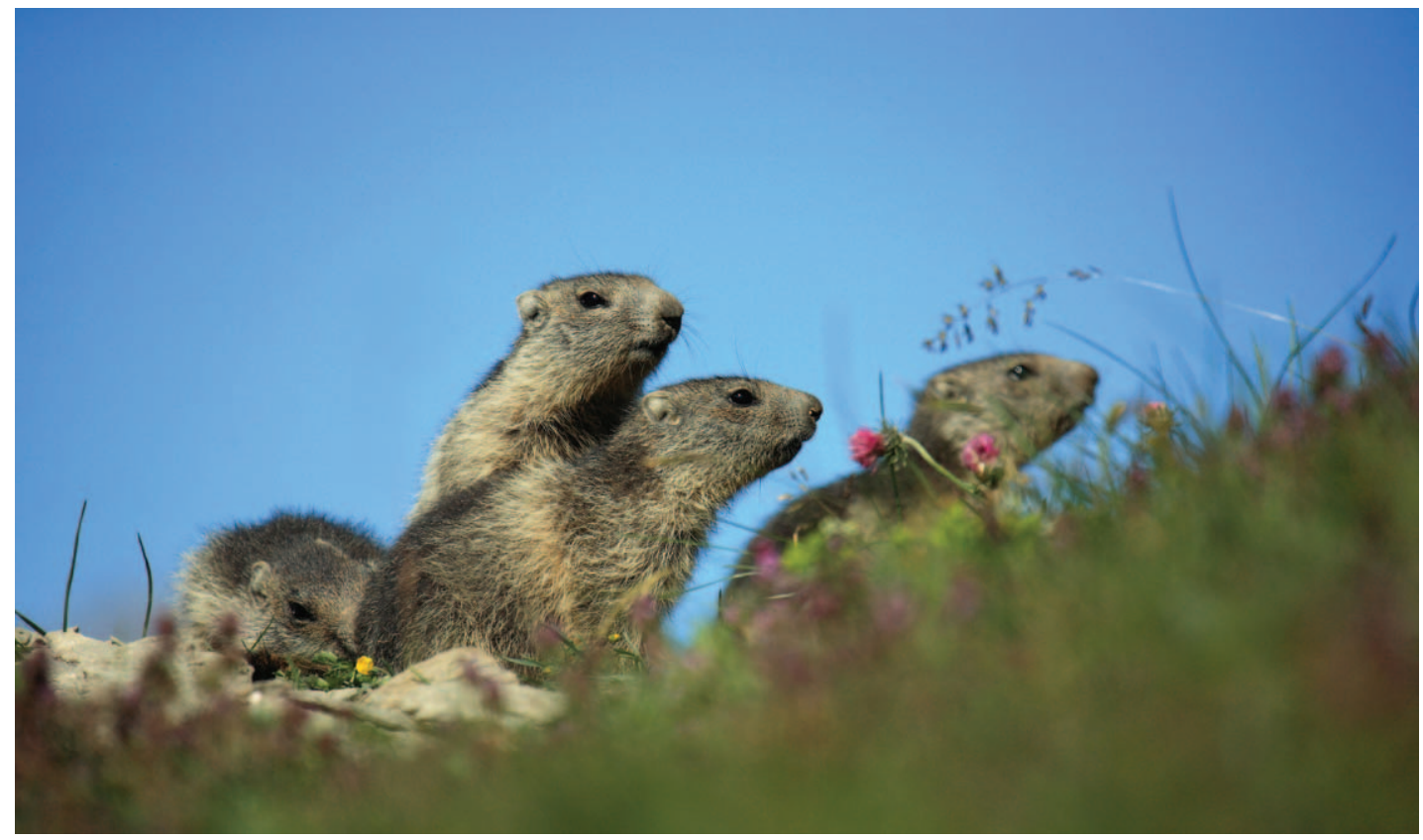

Alpine marmot subordinates playing at Grande Sassière nature reserve (French Alps). Photo credit: Carole Favre-Bonvin and Denis FavreBonvin (www.lumieresdesalpes.fr). 